\title{
Economic Efficiency and Damage Awards in Personal Injury Torts
}

\author{
George A. Schieren \\ Professor of Economics \\ Appalachian State University \\ Boone, NC 28608 \\ telephone: 828-262-4033 \\ e-mail: schierenga@appstate.edu \\ fax: 828-262-6105
}




\section{Introduction}

Forensic economists have forever debated among themselves how to determine any and all of the various measures which they are called upon to calculate in a personal injury/wrongful death tort matter - present value, projected earnings, employment and work life probabilities, personal consumption, etc. Recently, however, discussion has begun to arise concerning exactly what should be measured, in addition to how to measure. The argument about "earnings" versus "earnings capacity” has been around for some time, as have several other issues such as whether lost earnings net of taxes or gross earnings are appropriate and what should be measured as the loss in the death of a child. More recently, the arguments about "hedonic damages" - the "value" of a life measured in some fashion, either including economic earnings and/or pain and suffering, or not including them - is at least partially responsible for renewed discussion about what should be measured.

While most of the debate about hedonic damages has been about the appropriateness of various measures of the "quality of life," the mere rise of testimony and depositions ascribing specific large dollar values to the quality of life has engendered the appearance of research on exactly what should be measured as the loss in a personal injury/wrongful death legal matter. Calfee and Rubin (1992) and Schieren (1998) have made the argument that it is not economically efficient for a defendant to pay money to replace something lost in an accident, when the "something" is irreplaceable by its very nature. In addition, Arlen (1992) has taken the question of what the defendant should pay relative to what the plaintiff should receive to a higher level with her exposition of why the defendant's wealth matters in determining the amount of the award.

This paper attempts to further the discussion about what should be measured in determining a damage award in a personal injury action (wrongful death is not considered) by expanding on the original ideas about economic efficiency and the tort system so well set forth in Landes and Posner (1987) and Shavell (1987). The background of the economic analysis of liability law and the roles of legal actions and forensic economists are briefly laid out in Section II. Section III presents a general model which is shown to collapse to the standard argument about economic efficiency under simplifying assumptions. In Section IV the implications of the model as a whole are examined and compared to Calfee and Rubin's results. Section $\mathrm{V}$ provides some conclusions, a summary, and ideas about the model's implications for forensic economics. 


\section{Background}

In general, economic efficiency (resource allocation) requires that all costs be internalized to avoid the over-production of the good or service. The two main branches of liability law - strict liability and negligence - attempt to force internalization in differing degrees. Under strict liability, an injurer (an entity which

causes an accident) is forced to pay the costs of the accident to the victim of the accident. If, in fact, the injurer always pays all the complete costs of the accident, it is obvious that the costs are internalized to the injurer. While it is equally obvious that imperfections in the tort system will cause less than 100 percent compensation in every case, the economic argument is that attempting to enforce strict liability will lead to greater economic efficiency, if not perfect efficiency.

Under strict liability with perfect compensation for all costs to the victim, the victim is indifferent between an accident or no accident and hence has no incentive to take precautions to avoid an accident. The injurer, on the other hand, has incentives to take precaution up to the point where the cost of the precaution equals the cost of the accident.

Negligence laws, on the other hand, allow the injurer to be free of liability if he takes "adequate” precaution. Negligence occurs if the injurer gains benefits (the money not spent on precaution) which are less than the expected costs to victims. In this instance - the famous Hand Rule - economic analysis very explicitly comes into play. As under strict liability, if there is perfect compensation in all accidents, economic efficiency will prevail.

The standard model in law and economics has come to be that there will be efficient resource allocation when the marginal cost incurred by the potential injurer in taking precaution to avoid an accident equals the expected marginal cost incurred by the victim. The standard formulation has assumed risk neutrality and monetary wealth as the only input to a linear utility function. Under these conditions, when the last dollar spent by an injurer on precaution to avoid an accident equals the probability of an accident times the loss of wealth suffered by a victim (the expected loss), efficient allocation of resources and Pareto optimality are achieved.

There are several questions left unanswered by this analysis. One is whether or not a dollar paid out by the injurer has the same utility to the injurer as the utility of a dollar lost by the victim. Arlen (1992) concludes that the wealth of the defendant does matter in determining a damage award under most circumstances, a conclusion shared by the model developed here later. The question of whether or not only monetary loss matters to economic efficiency is addressed by Calfee and Rubin (1992). Their cogent arguments conclude that, in fact, only the loss of wealth suffered by the victim matters. This is also a question addressed by this paper with a somewhat similar, but expanded conclusion.

Both of the studies cited above are concerned with what the damages 
awarded in a tort action should be - a question sorely absent from earlier discussion in law and economics because the emphasis was always on the efficient level of precaution. One question rarely addressed until recently is the role of a damage award in the context of the economic analysis of an actual tort action. One answer to the question of what role a damage award plays is that it is designed to make the victim "whole." This answer, however, is not an economic answer except insofar as the award restores property rights - the basis for our economic system. It does not deal with economic efficiency or optimality. The economic answer to the question would be that a damage award acts as a "signal" to the injurer - a signal used to determine efficient resource allocation.

As pointed out earlier, under strict liability, the injurer has incentives to take precaution up to the point where the cost of the precaution equals the cost of the accident. But how does the injurer know what the cost of an accident is or will be? While the injurer might be able to estimate the probability of an accident, without information from tort actions he is operating in the dark as to the cost of an accident. Therefore, the damages awarded in a tort action (perhaps involving another injurer instead of himself) are a way that a potential injurer can estimate the cost of an accident to use in his calculus of determining the efficient amount of precaution to take.

Again, with negligence the injurer needs to know the cost of accident in order to take the necessary amount of precaution and avoid being liable. Damage awards signal the injurer how much to spend on precaution. The system is far from perfect, with transaction costs and imperfect, asymmetrical information. It remains, however, as the system in place for conveying information about the costs of accidents to injurers. Therefore, the calculation of the damage award and, more particularly, what should constitute the damage award (what should be measured) is of paramount importance to enabling the system to function as efficiently as possible, even with its problems.

\section{The General Model}

Schieren (1998) set forth a utility model based on the idea of the victim's human capital. Without repeating the mathematical formulation here, it should be noted that any victim's utility is derived from leisure time, work time, and the consumption of things bought with earnings; all accumulated over time and with a physical and mental well-being to derive utility from these accumulated inputs. In this type of model there are inputs to the utility function which are non-replaceable in the event of any accident (e.g., lost time), inputs which may be non-replaceable (e.g., job satisfaction), and inputs which are always replaceable (e.g., money). In the model presented below, these are all subsumed into the category of "non-replaceable." In this model, the utility functions are any general function, and there is the possibility 
of a divergence between the amount paid in damages by the injurer and the amount received by the victim.

Assume the following:

$$
\begin{aligned}
& X \equiv \text { the dollar amount of care taken by the injurer } \\
& Y \equiv \text { the amount of monetary damages paid by the injurer } \\
& Z \equiv \text { the amount of monetary damages received by the victim } \\
& U_{v}^{n} \equiv \text { the amount of utility of the victim with no accident } \\
& U_{v}^{a} \equiv \text { the amount of utility of the victim with an accident } \\
& W_{v}^{n} \equiv \text { the wealth of the victim with no accident } \\
& W_{v}^{a} \equiv \text { the wealth of the victim with an accident } \\
& N R_{v}^{n} \equiv \text { the non-replaceable utility inputs of the victim with no accident } \\
& N R_{v}^{a} \equiv \text { the non-replaceable utility inputs of the victim with an accident } \\
& U_{v}^{n}=f_{v}^{n}\left(W_{v}^{n}\right)+g_{v}^{n}\left(N R_{v}^{n}\right) \\
& U_{v}^{a}=f_{v}^{a}\left(W_{v}^{a}\right)+g_{v}^{a}\left(N R_{v}^{a}\right) \\
& W_{I} \equiv \text { the wealth of the injurer with no accident and no care taken } \\
& U_{I}^{n} \equiv \text { the amount of utility of the injurer with no accident } \\
& U_{I}^{a} \equiv \text { the amount of utility of the injurer with an accident } \\
& U_{I}^{n}=U_{I}\left(W_{I}-X\right) \\
& U_{I}^{a}=U_{I}\left(W_{I}-X-Y\right) \\
& p(X) \equiv \text { the probability of an accident if } X \text { amount of care is taken }
\end{aligned}
$$

To maximize social utility rather than one individual's utility, it is necessary to maximize $S$, the sum of the expected utilities of the victim and the injurer.

$$
\begin{aligned}
S= & {[1-p(X)]\left[f_{v}^{n}\left(W_{v}^{n}\right)+g_{v}^{n}\left(N R_{v}^{n}\right)\right]+p(X)\left[f_{v}^{a}\left(W_{v}^{a}+Z\right)+g_{v}^{a}\left(N R_{v}^{a}\right)\right] } \\
& +[1-p(X)]\left[U_{I}\left(W_{I}-X\right)\right]+p(X)\left[U_{I}\left(W_{I}-X-Y\right)\right]
\end{aligned}
$$


The optimal amount of care to take is given by

$$
\begin{aligned}
\frac{\partial S}{\partial X} & =-\frac{\partial p(X)}{\partial X}\left[f_{v}^{n}\left(W_{v}^{n}+g_{v}^{n}\left(N R_{v}^{n}\right)\right]+\frac{\partial p(X)}{\partial X}\left[f_{v}^{a}\left(W_{v}^{a}+Z\right)+g_{v}^{a}\left(N R_{v}^{a}\right)\right]\right. \\
& +\frac{\partial U_{I}\left(W_{I}-X\right)}{\partial X}[1-p(X)]-\frac{\partial p(X)}{\partial X}\left[U_{I}\left(W_{I}-X\right)\right] \\
& +\frac{\partial p(X)}{\partial X}\left[U_{I}\left(W_{I}-X-Y\right)\right]+\frac{\partial U_{I}\left(W_{I}-X-Y\right)}{\partial X}[p(X)]=0
\end{aligned}
$$

Or,

$$
\begin{aligned}
& \frac{\partial U_{I}\left(W_{I}-X\right)}{\partial X}[1-p(X)]+\frac{\partial U_{I}\left(W_{I}-X-Y\right)}{\partial X}[p(X)] \\
& -\frac{\partial p(X)}{\partial X}\left\{\left[U_{I}\left(W_{I}-X\right]-\left[U_{I}\left(W_{I}-X-Y\right)\right]\right\}\right. \\
& =\frac{\partial p(X)}{\partial X}\left\{\left[f_{v}^{n}\left(W_{v}^{n}\right)+g_{v}^{n}\left(N R_{v}^{n}\right)\right]-\left[f_{v}^{a}\left(W_{v}^{a}+Z\right)+g_{v}^{a}\left(N R_{v}^{a}\right)\right]\right\}
\end{aligned}
$$

The standard analysis does not include $Y$ (amount paid in damages) and $Z$ (amount received by the victim), only the optimal amount of care. With $Y=Z=0$, with no consideration of non-replaceable inputs $(\mathrm{NR}=0)$, and with unchanged linear utility functions, the usual result is obtained.

$$
\frac{\partial U_{I}\left(W_{I}-X\right)}{\partial X}=\frac{\partial p(X)\left[W_{v}^{n}-W_{v}^{a}\right]}{\partial X}
$$

Or, 


$$
-1=\frac{\partial p(X)\left[W_{v}^{n}-W_{v}^{a}\right]}{\partial X}
$$

The optimal amount of care to be taken will be where the last dollar spent by the injurer to decrease $p$ equals the additional wealth not lost by the victim as a result of the decrease in $p$.

The general model presented here, however, allows for an altered utility function of the victim as a result of the accident and both wealth and non-replaceable inputs for the victim's utility function. It also recognizes that the optimal amount of damages paid by the injurer might not be the optimal amount of money received by the victim. Also, the amount of care taken by the injurer is a function of the amount it pays out and the amount received by the victim. This results from the signaling nature of the damage awards, no matter how the injurer makes the estimate of damages. He has to have some idea of the amount of the damages incurred and paid out, or he has no idea how much care to take.

$$
X=b(Y, Z)
$$

Therefore (since the probability of an accident is a function of the amount of care taken),

$$
c(Y, Z)=\text { the probability of an accident for a given level of care, determined }
$$

by the amount paid out in damages by the injurer and the amount received by the victim. Then the sum of the expected utilities of the injurer and victim would be

$$
\begin{aligned}
S & =[1-c(Y, Z)]\left[f_{v}^{n}\left(W_{v}^{n}\right)+g_{v}^{n}\left(N R_{v}^{n}\right)\right]+c(Y, Z)\left[f_{v}^{a}\left(W_{v}^{a}+Z\right)+g_{v}^{a}\left(N R_{v}^{a}\right)\right] \\
& +[1-c(Y, Z)]\left[U_{I}\left(W_{I}-X\right)\right]+c(Y, Z)\left[U_{I}\left(W_{I}-X-Y\right)\right]
\end{aligned}
$$


The optimal amount of $\mathrm{Z}$ would be determined by

$$
\begin{aligned}
& c(Y, Z)\left[\frac{\partial_{v}^{a}\left(W_{v}^{a}+Z\right)}{\partial Z}+\frac{\partial\left(U_{I}\left(W_{I}-X-Y\right)\right.}{\partial Z}-\frac{\partial U_{I}\left(W_{I}-X\right)}{\partial Z}\right]+\frac{\partial U_{I}\left(W_{I}-X\right)}{\partial Z} \\
& =\frac{\partial c(Y, Z)}{\partial Z}\left\{\begin{array}{l}
{\left[f_{v}^{n}\left(W_{v}^{n}\right)+g_{v}^{n}\left(N R_{v}^{n}\right)\right]-\left[f_{v}^{a}\left(W_{v}^{a}+Z\right)+g_{v}^{a}\left(N R_{v}^{a}\right)\right]} \\
+U_{I}\left(W_{I}-X\right)-U_{I}\left(W_{I}-X-Y\right)
\end{array}\right\}
\end{aligned}
$$

or,

$$
\begin{aligned}
\frac{\partial S}{\partial Z} & =-\frac{\partial c(Y, Z)}{\partial Z}\left[f_{v}^{n}\left(W_{v}^{n}\right)+g_{v}^{n}\left(N R_{v}^{n}\right)\right]+\frac{\partial c(Y, Z)}{\partial Z}\left[f_{v}^{a}\left(W_{v}^{a}+Z\right)+g_{v}^{a}\left(N R_{v}^{a}\right)\right] \\
& +\frac{\partial_{v}^{a}\left(W_{v}^{a}+Z\right)}{\partial Z}[c(Y, Z)]-\frac{\partial c(Y, Z)}{\partial Z}\left[U_{I}\left(W_{I}-X\right)\right] \\
& +\frac{\partial\left(W_{I}-X\right)}{\partial Z}[1-c(Y, Z)]+\frac{\partial c(Y, Z)}{\partial Z}\left[U_{I}\left(W_{I}-X-Y\right)\right] \\
& +\frac{\partial U_{I}\left(W_{I}-X-Y\right)}{\partial Z}[c(Y, Z)]=0
\end{aligned}
$$

The optimal amount of Y would be determined by 


$$
\begin{aligned}
\frac{\partial S}{\partial Y} & =-\frac{\partial c(Y, Z)}{\partial Y}\left[f_{v}^{n}\left(W_{v}^{n}\right)+g_{v}^{n}\left(N R_{v}^{n}\right)\right]+\frac{\partial c(Y, Z)}{\partial Y}\left[f_{v}^{a}\left(W_{v}^{a}+Z\right)+g_{v}^{a}\left(N R_{v}^{a}\right)\right] \\
& -\frac{\partial c(Y, Z)}{\partial Y}\left[U_{I}\left(W_{I}-X\right)\right]+\frac{\partial U_{I}\left(W_{I}-X\right)}{\partial Y}[1-c(Y, Z)] \\
& +\frac{\partial c(Y, Z)}{\partial Y}\left[U_{I}\left(W_{I}-X-Y\right)\right]+\frac{\partial U_{I}\left(W_{I}-X-Y\right)}{\partial Y} c(Y, Z)=0
\end{aligned}
$$

or,

$$
\begin{aligned}
& c(Y, Z)\left[\frac{\partial U_{I}\left(W_{I}-X-Y\right)}{\partial Y}-\frac{\partial U_{I}\left(W_{I}-X\right)}{\partial Y}\right]+\frac{\partial U_{I}\left(W_{I}-X\right)}{\partial Y} \\
& =\frac{\partial c(Y, Z)}{\partial Y}\left\{\begin{array}{l}
{\left[f_{v}^{n}\left(W_{v}^{n}\right)+g_{v}^{n}\left(N R_{v}^{n}\right)\right]-\left[f_{v}^{a}\left(W_{v}^{a}+Z\right)+g_{v}^{a}\left(N R_{v}^{a}\right)\right]} \\
+\left[U_{I}\left(W_{I}-X\right)\right]+\left[U_{I}\left(W_{I}-X-Y\right)\right]
\end{array}\right\}
\end{aligned}
$$

These two equations, (9) and (11) conceptually can be used to determine the two unknowns, Y and Z. The analysis is greatly simplified, however, if it is recognized that the way the system works is for the amount paid by the injurer to equal the amount received by the victim. Then

$$
\frac{\partial c(Y, Z)}{\partial Y}=\frac{\partial c(Y, Z)}{\partial Z}
$$

and the right-hand sides of Equations (9) and (11) are equal.

$$
\begin{aligned}
& \frac{\partial U_{I}\left(W_{I}-X-Y\right)}{\partial Y}-\frac{\partial U_{I}\left(W_{I}-X\right)}{\partial Y} \\
& =\frac{\partial f_{v}^{a}\left(W_{v}^{a}+Z\right)}{\partial Z}+\frac{\partial U_{I}\left(W_{I}-X-Y\right)}{\partial Z}-\frac{\partial U_{I}\left(W_{I}-X\right)}{\partial Z}
\end{aligned}
$$


Because $X=b(Y, Z)$,

$$
\frac{d U_{I}\left(W_{I}-X-Y\right)}{d Y}=-\frac{\partial U_{I}\left(W_{I}-X-Y\right)}{\partial Y}-\frac{\partial X}{\partial Y}\left[\frac{\partial U_{I}\left(W_{I}-X-Y\right)}{\partial Y}\right]
$$

and

$$
\frac{d U_{I}\left(W_{I}-X-Y\right)}{d Z}=\frac{\partial U_{I}\left(W_{I}-X-Y\right)}{\partial Z}\left[-\frac{\partial X}{\partial Z}\right]
$$

Then Equation (12) becomes

$$
\begin{aligned}
& -\frac{\partial U_{I}\left(W_{I}-X-Y\right)}{\partial Y}-\frac{\partial X}{\partial Y}\left[\frac{\partial U_{I}\left(W_{I}-X-Y\right)}{\partial Y}\right] \\
& =\frac{\partial f_{v}^{a}\left(W_{v}^{a}+Z\right)}{\partial Z}-\frac{\partial X}{\partial Z}\left[\frac{\partial U_{I}\left(W_{I}-X-Y\right)}{\partial Z}\right]
\end{aligned}
$$

If $K \equiv Y=Z$, then

$$
\frac{\partial f_{v}^{a}\left(W_{v}^{a}+K\right)}{\partial K}=-\frac{\partial U_{I}\left(W_{I}-X-K\right)}{\partial K}
$$

Equation (16) shows that the marginal utility lost by the injurer with the last dollar paid in damages, given the level of care, equals the marginal utility gained by the victim from the last dollar of damages received - a not surprising result for economists familiar with Pareto optimality. 


\section{Implications of the Model}

The optimal amount of damages paid and the optimal amount received as shown in Equation (16), hereafter referred to as the optimal conditions, reveal several interesting results when considering a tort action from an economic analysis perspective. First, the optimal conditions clearly support Arlen's contention that the defendant's wealth does matter, as indicated by the marginal condition of the injurer's general utility function in Equation (16). The utility lost by a General Motors’ paying a ten million dollar award is not necessarily the same as the utility gained by the plaintiff's receiving ten million dollars. This raises the obvious question, brought out by others, of how to deal with the defendant paying one amount and the plaintiff receiving a different amount.

Secondly, the optimal conditions do not include the non-replaceable inputs to the victim's utility function, just as Calfee and Rubin contend. This is indicated in the inclusion of only wealth and the damage award as arguments in the victim's utility function appearing in the optimal conditions. This is the condition that a number of forensic economists prefer not to accept. After all, if a wealthy defendant is liable for an accident which results in the victim's losing both legs, why is not the victim entitled to two or three million dollars? Clearly there has been an incredible loss. The answer is cold-hearted economic efficiency, but as is discussed below, it is not as cold-hearted as might first appear.

One aspect of the optimal conditions is that the relevant marginal utility of the

victim is derived only from the utility function after the accident $-f_{v}^{a}$. This very crucial aspect of the optimum is often ignored, as is the fact that the conditions are expressed as marginal utility. Taken together, these conditions render the idea of making the defendant "whole" inconsistent with economic efficiency and Pareto optimality. The following graphical analysis, derived from Calfee and Rubin and with all the figures referring to the victim's utility, is helpful in making this clear.

Figure 1 shows the simplest case where there is no change in the victim's utility function, only a loss of wealth and non-replaceable inputs. Assuming equilibrium before the accident (equal marginal utilities) with inputs $N^{n}$ and utility $U^{n}$, and decreasing marginal utility, the optimal conditions would dictate a transfer of wealth from the injurer to the victim in the amount of no more than $\left[N^{n}-N^{a}\right]$ to restore equilibrium at the victim's pre-accident marginal utility. Note that this amount $\left[N^{n}-N^{a}\right]$ could include additional compensation above the lost wealth as an offset to some of the lost non-replaceable inputs (pain and suffering?).

Figure 2 presents the case of a parallel shift downward in the victim's utility function as a result of the accident. From the point $\left(N^{n}, U^{n}\right)$ before the accident, the victim's total utility decreases to $U^{a}$ with a loss of inputs to $N^{a}$ and the shift in the utility function. To restore equilibrium, the damage award received by the victim 
should be no more than $\left[N^{n}-N^{a}\right]$. At the point $\left(N^{n}, U^{o}\right)$ the original equilibrium

Figure 1.

Victim's Utility Function - Unchanged

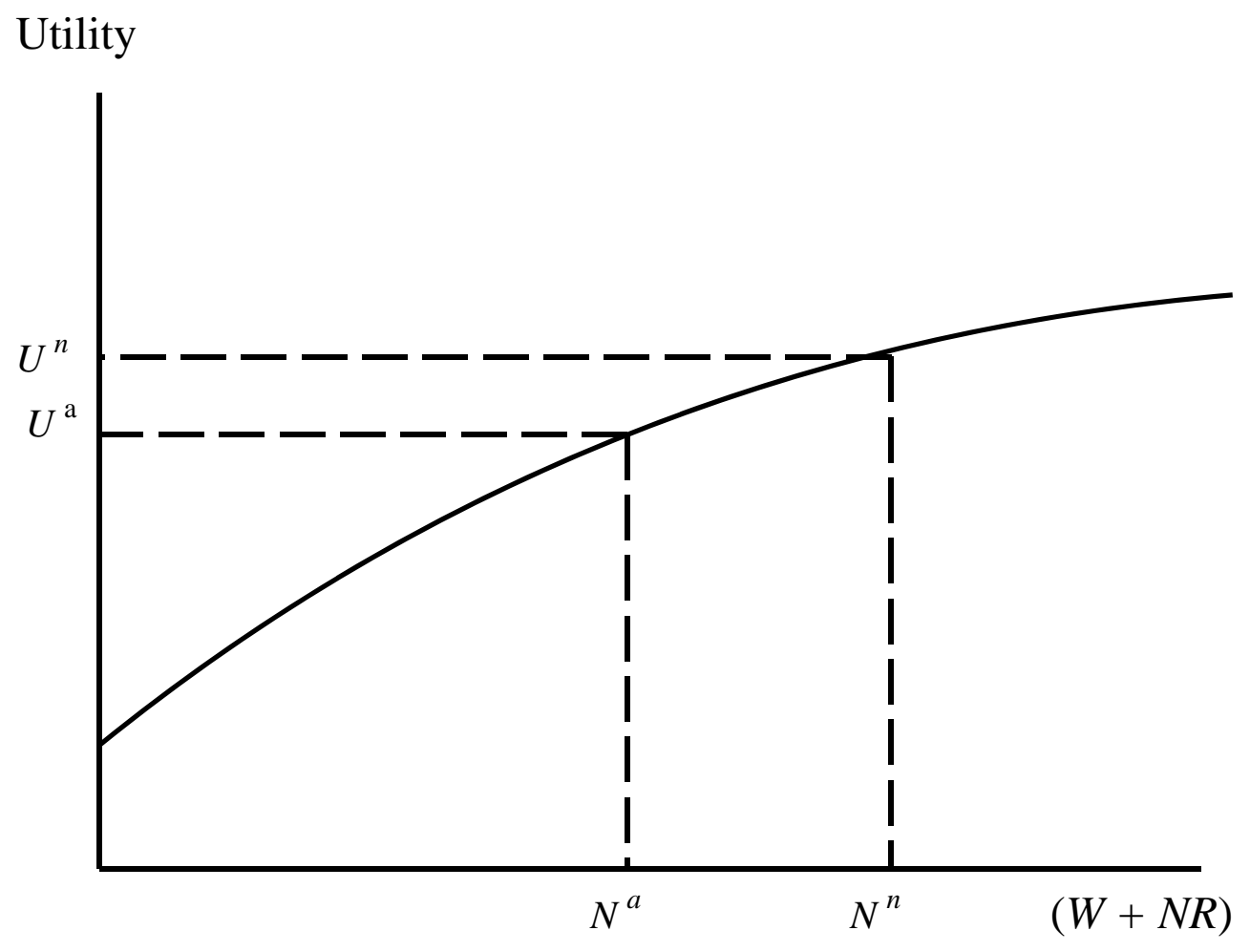

marginal utility of the victim has been restored. To return the victim to her preaccident level $U^{n}$ would require additional money in the damage award, providing her with $N^{b}$ of wealth - far in excess of her no-accident state of $N^{n}$. In light of her decreasing marginal utility of wealth, to transfer $\left[N^{b}-N^{a}\right]$ to her would be to reduce total utility in the system as wealth becomes an input for the victim at a lower marginal utility point than the equilibrium conditions before the accident.

In Figure 3 the utility function shifts downward and has an altered shape. After the accident, at the point $\left(N^{a}, U^{a}\right)$, the victim has a higher marginal utility of wealth compared to the equilibrium before the accident. The victim should receive $\left[N^{n}-N\right.$ ${ }^{a}$ ] only if that is the point where the marginal utility of wealth for the victim based on 
his after-accident utility function equals the marginal utility given up by the injurer

Figure 2.

\section{Victim's Utility Function - Parallel Shift Down After the Accident}

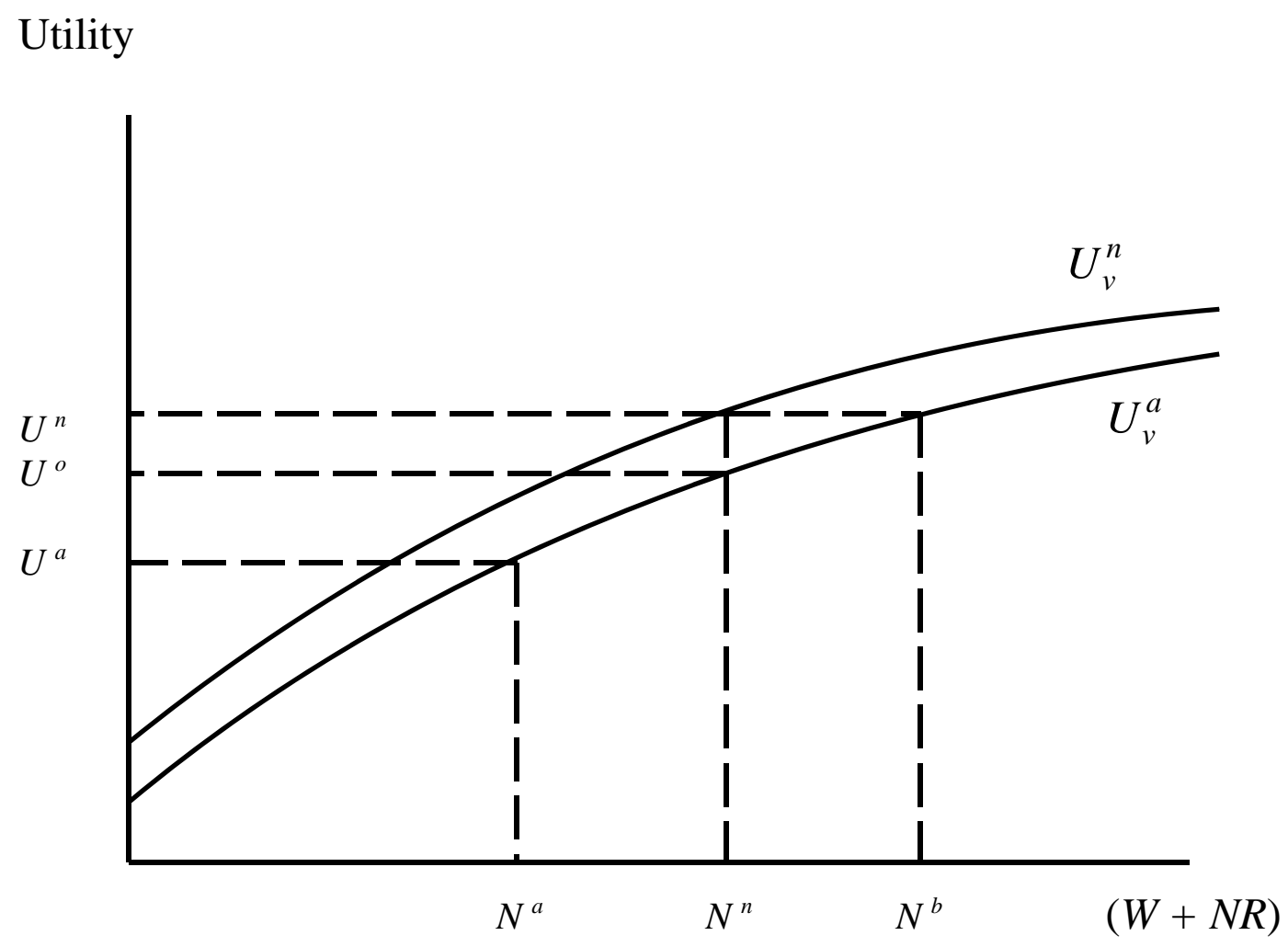

in paying the award. If this point happens to be $N^{\circ}$, then the victim does not receive the compensation of $\left[N^{n}-N^{a}\right]$ to fully restore the inputs to his utility function.Note, however, that the inputs are both wealth and the non-replaceable inputs. The entire wealth could be restored at that point, but not the non-replaceable inputs. The point of equal marginal utilities could be $N^{b}$ if the marginal utility of the victim after the accident is still above the pre-accident marginal utility. Conceptually, the victim could end up with a much greater amount of wealth and a higher level of utility if the afteraccident utility function has the necessary shape for such a result.

How realistic is the idea of an increased marginal utility after an accident? 
With a great loss of wealth, a victim who also lost both legs would derive a large amount of utility from a hundred thousand dollars (above lost earnings) to purchase special equipment and undergo special training.

Figure 3.

\section{Victim's Utility Function - Shifted Down After the Accident, and with Marginal Utility Decreasing Slower than Before the Accident}

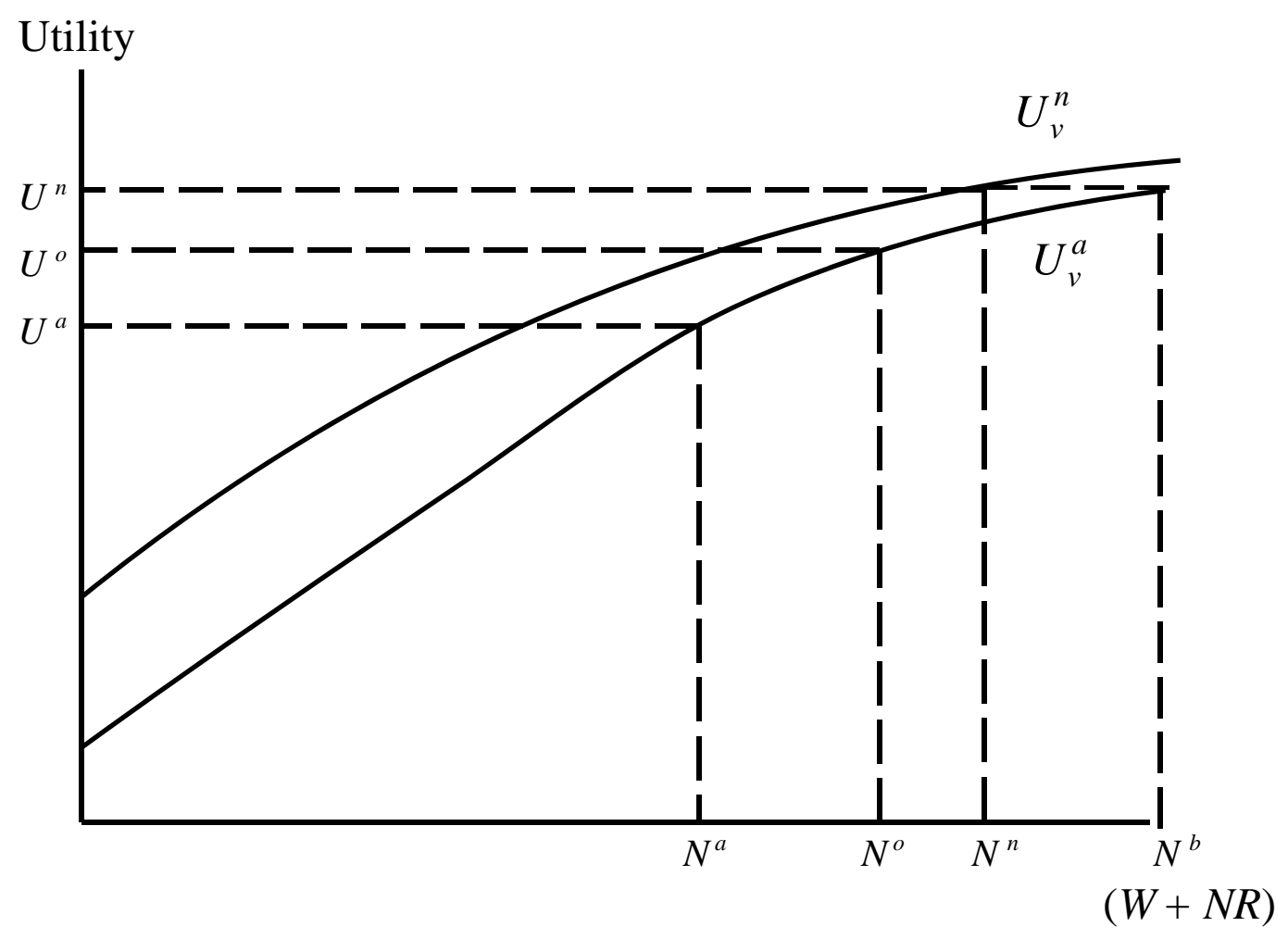

On the other hand, it would be expected that there is a limit beyond which the victim's marginal utility is not greater than before the accident and possibly is less; i.e., the utility function flattens out. He has his income replaced and his special needs taken care of to restore him as much as possible to the pre-accident state, but at some point transferring wealth from the injurer to the victim will result in less total utility for society. Where is that point? It seems impossible for anyone to know that with any 
precision.

The final scenario is presented in Figure 4. This situation encompasses a loss of wealth and non-replaceable inputs and a shift of the utility function with a reduced marginal utility. Awarding the victim damages of $\left[N^{n}-N^{a}\right]$ will leave her with less total utility at $U^{o}$, and at that point $\left(N^{n,} U^{n}\right)$ the marginal utility is less than in the noaccident state $\left(N^{n}, U^{n}\right)$. In this graphical depiction it is impossible for the victim to be returned to her level of utility before the accident, no matter how much wealth is transferred from the injurer to the victim. How much should be transferred? According to the optimum conditions, wealth should be taken from the injurer and wealth awarded to the victim until the marginal utility given up by the injurer is equal to the marginal utility gained by the victim.

Where is this point? It depends on the utility function of the injurer and the after-accident utility function of the victim. Since both of these are clearly unknown, it is impossible for a forensic economist or anyone else to definitively say.

\section{Conclusions}

Two reminders and two additional caveats should be stressed. The optimal conditions derived above are optimal only in the world of economic efficiency. No notion of "equity" has been introduced. And the analysis has all been for personal injury, not wrongful death. Since a deceased person has no utility function, it is impossible to do this type of analysis for a wrongful death situation.

Also, the only utility functions considered were those of the injurer and the victim. The utility functions of those people around the victim (family, friends, etc.) were not included in maximizing social welfare. To the extent that one person's presence (not his wealth) contributes positively to another person's utility, then that should be considered in a perfect world, but this paper has made no attempt to analyze what any person other than the victim should receive as a damage award. This type of analysis might be appropriate in considering wrongful death and the utility loss to society.

Finally, the analysis presented here is only of a static nature. To consider a dynamic system subject to changing over time is beyond the scope of this paper. However, as additional research becomes available, especially in disciplines studying "happiness" (analogous to economists" “utility”) it may become possible to consider the changing nature of utility functions over time; i.e., a victim's utility function shortly after injury compared to her utility function five years later. 
Figure 4.

Victim's Utility Function - Shifted Down after the Accident, and with Marginal Utility Decreasing Faster than Before the Accident

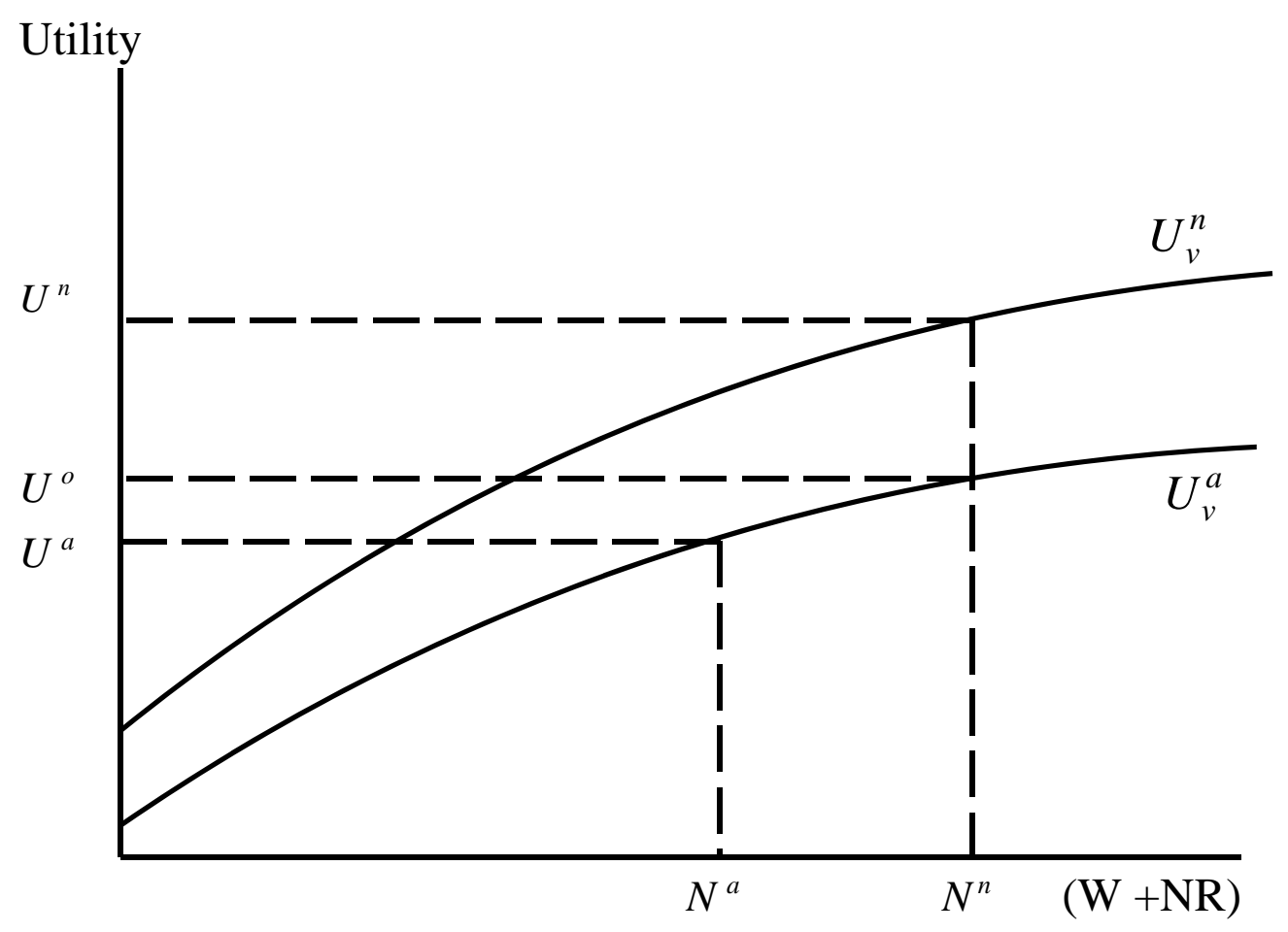

Repeating the optimal condition

$\frac{\mathscr{f}_{v}^{a}\left(W_{v}^{a}+K\right)}{\partial K}=-\frac{\partial U_{I}\left(W_{I}-X-K\right)}{\partial K}$

it can be seen that Pareto optimality and economic efficiency are directly dependent upon the utility function of the injurer, given some level of precaution taken, and the utility function of the victim after the accident. The simplifying assumptions made in 
early law and economics analysis are made at too high a cost when applied to the reality of a tort action. There is nothing in the more general model presented here that has economic analysis concluding that the victim should be "made whole" in the sense of restoring him to his pre-accident level of utility. In fact, only two of the possible scenarios of the victim's utility even allow the possibility of restoring him to that pre-accident level of utility - the simplest case with a completely unchanged utility function and the case with increasedmarginal utility of wealth after the accident.

What can be said about the amount of award a victim should receive? In almost all cases the monetary damages should be compensated as a minimum. [An exception might be the single executive making a million dollars a year before an accident reduces him to a bed-ridden quadriplegic. If a hundred thousand dollars a year will take care of him very comfortably, then economic efficiency says that is all he should receive. Anything beyond that has a marginal utility of zero to him obviously a lower marginal utility than the injurer would have.]

Anything beyond compensation for monetary damages (principally lost earnings - however that might be expressed), depends on the utility functions of both the injurer and the victim - in particular, the marginal utility derived from the nonlinear utility function of the victim after the accident. In addition to the victim not necessarily being restored to his pre-accident level of utility, the optimal conditions to not require that he be restored to the same marginal utility experienced before the accident in most cases. On the contrary, as the injurer moves down his utility function by giving up money as an award (Y), his marginal utility will be increasing. As the victim moves up his after-accident utility curve by regaining money through the award (Z), he will encounter ever-smaller marginal utility. In general, money will be transferred from the injurer's original equilibrium, moving him to a higher marginal utility point. As the victim receives the transfer, his marginal utility decreases based on his after-accident utility function and bearing no necessary relationship to his preaccident marginal utility. At some point the two marginal utilities will be equal, if the award paid and the award received are the same.

Therefore, there is nothing in the analysis of economic efficiency and Pareto opimality which dictates that the victim be returned to her pre-accident level of utility or even to her pre-accident marginal utility. It is more likely that the economic optimal conditions dictate that the victim not be restored to her pre-accident utility level. The two most important analytical points made here are: non-replaceable inputs to the victim's utility function should not be compensated for; and the relevant recognition of the victim's utility compensation is based on his utility function after the accident.

As for the jury, it is necessary to recognize two very important points about the real-world limitations of a tort action. First, no one can measure utility. But even more importantly, it has been shown here that even if utility could be measured, it 
would not be appropriate in terms of economic efficiency to compensate the victim for all her lost utility. How is a jury supposed to perform marginal utility calculations for something which cannot be measured and which is generated by unknown functions?

That is the jury's job, no matter how difficult it may be. It is possible to make academic suggestions as to what a jury does or should do, but what a forensic economist should not do is pretend that he or she knows, or can estimate, what the award should be to ensure optimal economic efficiency. 


\section{References}

Arlen, Jennifer H. “Should Defendant's Wealth Matter?” Journal of Legal Studies, 1992. XXI: 413-429.

Calfee, John E. and Paul H. Rubin, "Some Implications of Damage Payments for Nonpecuniary Losses.” Journal of Legal Studies, 1992. XXI: 371-411.

Cooter, Robert D. “Economic Theories of Legal Liability.” Journal of Economic Perspectives, 1991. V(3): Summer, 11-30.

Landes, William E. and Richard A. Posner, The Economic Structure of Tort Law, 1987. Cambridge, MA: Harvard University Press.

Shavell, Steven. The Economic Analysis of Accident Law, 1987. Cambridge, MA: Harvard University Press.

Schieren, George A. "The Economic Framework of Personal Injury/Wrongful Death Damages.” 1998. Journal of Forensic Economics 11(1): Winter, 33-46. 